\title{
Fostering inter-cultural dialogue - visionary intentions and the realities of a dedicated public space
}

\author{
Ronan Paddison ${ }^{1}$, Marilyn Keenan ${ }^{1}$ and Sophie Bond ${ }^{2 *}$ \\ 1 University of Glasgow \\ 2Victoria University of Wellington, New Zealand
}

\begin{abstract}
The recent advocacy of fostering inter-cultural dialogue as a means of achieving greater community cohesion raises the question of the fora through which this is likely to be achieved. While the spaces in which an awareness and respect for difference can develop spontaneously through community activism, much attention in policy circles has been given to the creation of more deliberate spaces in which such interaction can develop more meaningful - durable - interactions than the civilities of everyday light sociality. This paper explores the realities of a dedicated public space designed explicitly to foster greater inter-cultural contact and understanding, the Hidden Gardens in Glasgow. Intended as a space of contemplation as well as the celebration of diversity, the reality of its appreciation and usage is more diverse than had been initially envisaged.
\end{abstract}

Keywords: Inter-cultural dialogue, inter-ethnic contact, public space.

\section{The rise of inter-cultural dialogue}

The retreat from multiculturalism, particularly within policy circles, has been accompanied by a growing consensus around the value of building inter-cultural dialogue as the means of producing social harmony in ethnically diverse cities (Council of Europe, 2009; Commission on Integration and Cohesion, 2007; Wood and Landry, 2008). As the Council of Europe (2009) has argued, multiculturalism tended to foster communal segregation and mutual incomprehension rather than understanding. Added to this there were claims that multiculturalism undermined the rights of individuals, particularly women (Okin, 1997; Macey, 2009). The terrorist bombings in London in July 2007 and the riots earlier in the decade in several northern England towns were attributed, in part at least, to the failings of multiculturalism and its accentuation of separatism. If such a conclusion has been contested, alternative policy modes to multiculturalism were sought that would give more direct expression to the need for establishing social harmony while still respecting difference and diversity. Interculturalism, it has been argued, offers a compromise path between assimilation and multiculturalism based on the value of dialogue; for the Council of Europe inter-cultural 
dialogue offered "open and respectful exchange of views between individuals, groups with different ethnic, cultural, religious and linguistic backgrounds and heritage on the basis of mutual understanding and respect" (p.10). In other words, inter-culturalism was predicated as the means of respecting difference and of countering the tensions to which it gives rise.

Underpinning such dialogue is the fostering of 'meaningful interaction', the nature of which together with guidance notes on its implementation as well as advice on the mechanisms through which delivery can be made was to be the subject of a plethora of reports by the (UK) Department of Communities and Local Government (DCLG, 2008, 2009a, 2009b) together with the National Community Forum (2009) and the Commission for Racial Equality (2007). Meaningful interaction, it is assumed, will help build community cohesion through its ability to counter stereotyping and racial prejudice; as the results of the Citizenship Survey suggested, those who have friends from different ethnic backgrounds are more likely to have positive views of ethnic diversity. Yet, as social psychologists have debated, the fundamental assumption of contact theory - that it alters how we feel about the other in positive ways - remain contested (Dixon et al., 2005), added to which there has been less recognition than there should have been that interaction can take various forms, only some of which are likely to contribute in any durable sense to increasing respect between different groups.

Even accepting that interaction and inter-group contact can have positive outcomes on the feelings we have towards members of other groups, its achievement raises questions in turn as to what types of interaction are likely to achieve such an outcome and how it is to be attained (Holland, Clark, Katz and Peace, 2007). In particular, and in what is the prime focus of this paper, through what spaces is it likely to occur; in particular, can meaningful interaction be engineered through inspired design? Where public spaces are designed to foster inter-cultural understanding how do such spaces achieve their intended goal? How does agency influence the understanding of the designed space, and in particular are alternative readings, and usages, of it able to emphasise attributes of it other than those intended in its design? Empirically, the paper draws on the experience of a dedicated public space in Glasgow explicitly designed to celebrate diversity, the Hidden Gardens. The space has been cited in several reports as exemplifying 'good practice', notably in the Commission on Integration and Cohesion's report (2007) Our Shared Future. Our analysis adopts a more critical stance in demonstrating the problems underpinning the social engineering objectives it subsumed. The analysis draws on interviews conducted among those whose inspiration led to the creation of the Hidden Gardens, to those charged with its day-to-day running as well as survey evidence based on users of the space.

The ambitions of the Hidden Gardens were not dissimilar to those expressed through community cohesion - the fostering of shared values and common bonds promoted through social contact (Robinson, 2008). Yet, as much as community cohesion became a dominant policy trope that would be able to address a range of social problems through the reinvigoration of community, how this was to be achieved and what was the evidence for it was less apparent than was the vision set for it. The experience of the Hidden Gardens demonstrated the problems arising from the practice of community cohesion, specifically those linked to the creation of a public space dedicated to fostering meaningful interaction. 


\section{Charting inter-cultural dialogue: Meaningful interaction and public spaces}

The practice of inter-group interaction, and how it can be fostered, has become, not surprisingly, a key concern for policy guidance. Our Shared Future, the final report of the Commission on Integration and Cohesion (2007), has become a widely quoted reference much of which was devoted to how greater inter-group interaction could be achieved. The Commission in turn spurred the production of further guidance publications setting out the rationale for establishing community cohesion, through positive interaction (DCLG, 2009a), building a local sense of belonging (DCLG, 2009b) together with the means for ensuring delivery (2009c). As with Our Shared Future, these later studies worked within the assumption that meaningful interaction would have positive outcomes for community cohesion, but did not do so necessarily in an uncritical language. Critically, diversity itself was envisaged as having potentially negative impacts on cohesion, particularly in urban and rural areas newly exposed to its emergence, as well as in inner city areas which had a longer tradition of ethnic diversity and more recently of 'super diversity' (CIC, 2007; Vertovec, 2007). That diversity was characteristic of different types of area meant also that fostering meaningful interaction had to be contextually sensitive - that, as much as cohesion may be relevant to different geographical areas, its resolution needed to be local, limiting the portability of 'good practice' between areas.

In charting the basis for building social cohesion four types of meaningful interaction are defined in the DCLG report basing itself on an earlier study by the Commission for Racial Equality (CRE, 2007) - 'grounding', 'banal', 'opportunity' and 'growth'. While the first refers in essence to bonding social capital and to the reaffirmation of one's own identity, the latter two are closer to the achievement of bridging social capital either through networking in which people of different backgrounds are brought together ('opportunity interactions') or through more deliberate action in which people seek to explore the identities of members of other groups, an action which might reverberate on how self-identities are read and expressed. Banal interactions, by definition, are the civilities that people express towards each other, including those of different ethnicity, as a means of negotiating everyday life. While opportunity and, particularly, growth interactions were implied as providing the most explicit expression of building social cohesion the report also suggested that (the four types) can take place in a cycle - so that each supports the other and people can move back and forward between the different types' (DCLG, 2008: 9).

The premise on which 'meaningful interaction' is based is that its harnessing is likely to lead to greater respect for difference in ethnically diverse societies. For the most part - as Laurier and Philo (2006) and Thrift (2005) have argued - people do behave courteously towards strangers in public space. Yet, as Valentine (2008) has also argued everyday civilities should not be extrapolated as implying the respect for difference. The minor civilities that we engage at a mundane level reflect tolerance which may fall far short of constituting mutual respect in spite of their contribution to maintaining social harmony. Such interaction is likely too to be fleeting, constitutive of what Amin and Thrift (2002) define as 'light sociality' which, however important to maintaining social harmony, is not able to embrace a deeper understanding of difference.

To Amin (2002; 2012) fostering intercultural understanding would mean the creation of spaces of interdependence in which cross-cultural engagement can take place. Clearly, this raises the question of how such spaces are created and where they are likely to emerge, particularly where so much interaction at a mundane level is banal. Two types of such space can be defined, those arising serendipitously and those 
whose origins are more deliberate. Serendipitous spaces able to foster intercultural dialogue emerge in a variety of local contexts, but, by definition, accidentally rather than planned. Chance encounters can arise in the workplace, in consumption spaces, in pubic institutions such as hospitals, each of which can function as arenas for positive interaction. For Burnett (2012) meaningful inter-cultural interaction is likely to be rooted in spontaneous community activism - opposing a development proposed to the local area, for instance - rather than it is to develop from deliberate (probably 'topdown') intervention (see also Pask, 2010). In the recent experience of the area of Glasgow in which the Hidden Gardens are located both types of space were to emerge, the Gardens as a planned space and a more spontaneous political space resulting from opposition to the closure of the local public swimming baths (Paddison and Sharp, 2007). Grassroots protest did build bridging capital between members of different ethnic groups, initially as united opposition to the closure but more fundamentally in raising awareness and respect for difference. It was to such outcomes, but through very different means, that the Hidden Gardens sought to foster greater intercultural understanding.

\section{Initiating the hidden gardens}

The Hidden Gardens is a planned green space dedicated to peace and intercultural understanding located in the inner city of Glasgow in neighbourhoods which are characterized by high levels of ethnic diversity (Table 1). The choice was deliberate not only was it the most ethnically diverse area in Scotland, which since the 2001 Census has become more diverse with the arrival of a significant Roma population together with asylum seekers, but it was characterized by high levels of relative deprivation, particularly in Govanhill. A mixed, largely working class area, social relations in it could be fragile though by no means fraught. Where grassroots activism had helped to create meaningful interaction across ethnic groups, it existed alongside tensions that could, and on occasion have, bubbled to the surface, as between youth groups. Developing the Gardens, then, was seen as responding to the social needs of the area.

Table 1: Ethnic Composition of Govanhill and East Pollokshields, Glasgow 2001

\begin{tabular}{|c|c|c|c|c|c|c|}
\hline & $\begin{array}{c}\text { Total } \\
\text { Population }\end{array}$ & $\begin{array}{c}\text { White } \\
\text { Scottish }\end{array}$ & $\begin{array}{l}\text { Other } \\
\text { White }\end{array}$ & $\begin{array}{l}\text { South } \\
\text { Asian }\end{array}$ & Black & Other \\
\hline Govanhill & 7807 & $\begin{array}{l}5852 \\
(75.0)\end{array}$ & $\begin{array}{l}743 \\
(9.5)\end{array}$ & $\begin{array}{l}1040 \\
(13.3)\end{array}$ & $\begin{array}{c}45 \\
(0.6)\end{array}$ & $\begin{array}{l}127 \\
(1.6)\end{array}$ \\
\hline East Pollokshields & 8097 & $\begin{array}{l}3593 \\
(44.4)\end{array}$ & $\begin{array}{l}602 \\
(7.4)\end{array}$ & $\begin{array}{c}3739 \\
(46.2)\end{array}$ & $\begin{array}{c}23 \\
(0.2)\end{array}$ & $\begin{array}{c}145 \\
(1.8)\end{array}$ \\
\hline Glasgow & 577869 & $\begin{array}{c}503614 \\
(87.1)\end{array}$ & $\begin{array}{c}42745 \\
(7.5)\end{array}$ & $\begin{array}{c}21760 \\
(3.8)\end{array}$ & $\begin{array}{l}1792 \\
(0.3)\end{array}$ & $\begin{array}{l}7958 \\
(1.3)\end{array}$ \\
\hline
\end{tabular}

Note: Percentage values in brackets

Source: Derived from Census of Population, 2001

The idea for the Gardens was spearheaded by an arts based organization, NVA, and in particular by the vision of its charismatic founder. His vision was to be critical in defining the ethos for the space and its realization. The choice of the term 'gardens' was deliberate. As a garden, it was not a park: it was to be a more 'private' space conveyed through the notion of how different cultures and religions use horticulture and design to create spaces that function as places of refuge and contemplation. In this sense the Gardens were to appeal to abstract sensibilities of intercultural 
appreciation while simultaneously being a physical space in which celebration of cultural (and especially religious) diversity could be given material expression. Clearly, not only were the Hidden Gardens to be carefully planned but its intentions were premised in social engineering.

The design of the space was the culmination of two threads brought together under the careful project management of NVA - first, a spiritual sense of what it means to engage with an environment on multiple levels, and second, a respect for individuals rooted deeply in pluralism. The first set of ideas was initiated from NVA's artistic direction and the landscape architects approach to design. The garden was in the first instance, an arts-based project, rested in the belief that art can be a technique for generating social change. NVA's earlier work had involved large events in predominantly rural landscapes that shaped a particular experience of an environment but that simultaneously recognised the multiplicity of individual engagement with that landscape in that moment in time. For NVA, the initial ideas for the Hidden Gardens built on this trajectory and sought to bring spirituality and landscape together in a garden that explored the historicity and relational character of the place and allowed individuals to experience it on their own terms.

The second principle centred on a deep commitment to the pluralism that characterized the local area. Key here to tapping into this pluralism was the building in of local participation as to how the Gardens should be designed including what should be their content. The opinions and support of a wide range of local residents encompassing not only different ethnic and religious groups but also the young and asylum seekers - were sought working through a community liaison officer who functioned as an interlocutor between the local community and the NVA. The dialogue helped to introduce the intentions of NVA and the landscape architects to local residents in what was an ambitious refurbishment of a derelict neighbourhood space. More detailed negotiations between local community groups and artists centred on the installation of specific artworks and horticultural developments dedicated to different faiths.

The site itself was inauspicious and has consistently proved a challenge to the visibility of the Gardens even for local residents: located at the back of a former tram depot, which itself had been refurbished as a cultural venue, the site was in a sense literally 'hidden'. Even several years after its opening in 2003 the Gardens were not necessarily widely known of by local residents - as one interviewee admitted 'I grew up across there (pointing to tenements in a nearby street) and saw the Hidden Gardens from the outside, it changed the look of the space, but I never came in here' (Sikh, male 17 years).

\section{Readings of the gardens}

For NVA and the landscape designers the ambitions for the Hidden Gardens were visionary and rooted in the ability of the artist to design a space so as to shape people's reading of the environment. Specifically this was to be achieved through a range of interventions, mainly but not exclusively, centred around the use of plants and trees that related to different faiths. That it was visionary was critical to both the inception of the Gardens and how it was to be realized. In other words, while how it could be realized in detail was influenced through community consultation, this deliberation was not allowed to change the fundamental vision set for the Gardens. As a vision it was aspirational in bringing awareness to different faiths as a means of confirming respect for difference as well as by virtue of its inclusiveness and as a space for peace and contemplation. 
If the aim of the Gardens, particularly for NVA, was to raise awareness of difference, then the extent to which the space is read by its users becomes of obvious importance. For some visitors these visions were borne out in their appreciation of the Gardens. As one respondent who had been brought up locally but who was now living in Japan expressed it:

It is a real garden, it feels like your own garden but bigger. It is not too elaborate. It is a place for quiet reflection. You go to the park to kill time or use up kid's energy but you would come here for more personal reasons. I live abroad where I am the foreigner. What is needed is acceptance. I am never going to be Japanese. Difference is good and that is what makes the Hidden Gardens good. Spiritual meaning is invited here, but is very personal. Anyone can be accepted here. (Female, 50s)

Others were similarly sympathetic with the broad aims and on why the term 'Gardens' was used rather than 'park':

The Hidden Gardens are special because they are hidden in an urban space where many people don't have gardens of their own. It is a serene space in a built up area.

For some the preference for the space as a garden rather than a park accentuated its safety:

The best thing about the gardens is that it is very family oriented. The surrounding is good for babies, very inclusive and I don't mind coming by myself as it is very safe. It is not like a park where kids can get on the road or something. (Female, mother, early 30s)

Yet, while safety is implicit in the Gardens being a refuge of peace and contemplation, its foregrounding substitutes for the original purpose intended for the space.

If the Gardens as a safe space represents an 'alternative' reading, for some visitors the purpose of the space was questioned more directly. One interviewee, himself a youth worker working with different faith communities elsewhere in the city, questioned the role of a dedicated space:

(While agreeing) that 'dedicated spaces like the Hidden Gardens are needed... (he continued) "If you want to create community it must be intentional....A space in itself is not enough, however, plays and programmes are needed too. It must be an intentional process. Spaces labeled in such a way alone do not create communities. Things must be in place to bring people together. It is naive to think that space alone will result in community. You need to reflect on the difference and diversity in communities and ask how can these people enrich your life? (Male 20s)

Such a reading reflects the professional expertise of the interviewee, though expressed more bluntly it was felt by other users of the space:

I don't think that engineering a space is the way to get interaction. People need to talk - this doesn't make people interact at all. 
He continued:

I don't think that the park (sic) causes problems, it just doesn't solve any either. Some people aren't private about faith..... have never seen any minority groups, just white people with babies. (Male, late teens)

The last reading may be an over-statement though the perception that the Gardens had become a 'white space' was expressed by others, who indeed went on to make a further distinction centred on class:

"It is a very white middle class space and that may put other people off" (Female, 50s)

Or as another user expressed it more fulsomely:

I don't think that it is possible to dedicate a space like this to promote multiculturalism. If you look around today you can see there isn't much diversity here at all...Unless there are reasons to come, then everyday the Gardens are not really diverse. Faith and difference are not really approached everyday. You would never come to the Gardens thinking about contemplating faith or anything, you just come because it's nice and safe (Female, 30s)

Her reading returns to the theme of safety, though arriving at it has involved the questioning of how the space relates to diversity and, indeed, whether the usage reflects the ethnic diversity of the surrounding neighbourhoods, questioning the essential purpose designed for the Gardens.

Evidently, how the Gardens have become used and are interpreted varies. For some - probably a relatively few - visiting the Gardens was a contemplative act and in that sense came closest to the aspirations of NVA; for probably a larger number, and particularly for parents with young children, the reasons for coming are focused more on issues other than diversity. Further, for neither does the space appear to really involve anything more than light inter-cultural interaction, fleeting courtesies between different users of the Gardens, but little conversational interaction. Being aware of difference might be achievable through silent acknowledgement but, as one of the interviewees cited expressed it, interaction is ultimately dependent on people talking to one another. It was this reality that opened up debates to which the artistic vision behind the creation of the space had given relatively little attention.

\section{Developing the gardens as a space for inter-cultural dialogue}

How the Gardens could or should evolve as a space for inter-cultural dialogue has been the source of ongoing debate, and sometimes tension, among the Gardens' management, reflecting wider questions as to how people use public green spaces, and how to foster dialogue between ethnic groups whose mundane interaction is so often fleeting. Allied to the ongoing meaning of the space and the contribution it could make to addressing local inter-cultural relations was the issue of sustainability; in particular, was the essentially ascetic vision of the Gardens sustainable and what would be its contribution to raising awareness of local residents to difference and its understanding? Thinking about the role of the Gardens and their future role was to raise wider questions that centre on the politics of recognition (Fraser, 1990). 
Both in its initial vision, and how the space was designed, the Hidden Gardens was an explicit expression of recognition. The (local) diversity of faiths and ethnicities was given material expression through the different plantings and other exhibits within the Gardens. More meaningful interactions between different cultural groups are in part a reflection of an awareness of difference and of its meaning - the Gardens, then, sought to raise awareness of the traditions of different religions, East and West, as expressed through horticulture. The dialogue was 'silent' - the plantings and other features 'did the talking' and thus nurtured a greater awareness of difference (and of similarities between multiple ethnic groups).

How the Gardens should inform its visitors of the cultural and faith diversity in contemporary Scotland became a key issue in the running of the space. As the community liaison officer employed by NVA expressed it

The main tension was about how far the Garden should be a place that people came in and explored themselves without any activity being programmed or anything being done within the Garden that interfered with people's personal take on it...

On the latter much debate centred on the absence of signage informing visitors of the meaning of the different horticultural installations and how they related to different faiths, a problem which was eventually resolved by the availability of audio-guides. It was a resolution that proved welcome to visitors while simultaneously maintaining the privacy with which the meanings of the Garden should be appreciated.

These tensions were to be repeated in the debate as to whether the space should be used to stage programmed events that celebrated religious diversity. Those more opposed to the holding of such events pointed not just to their episodic nature, but also to the fact that the Gardens in themselves were an explicit celebration of such diversity. Yet, in marking religious festivals, Diwali and Eid in particular, the performativity of the event added an extra dimension to the value of the space and were to become important dates in the local calendar across the ethnic divide. How and whether such events, however, contribute to building community cohesion remains contested.

Less debatable was that celebratory events offered a way of using the space to foster awareness of difference. Judging by the numbers attending the Eid celebrations they also strengthened the connections between the Gardens and the local population which, given the misunderstandings and conflict that had previously surrounded Eid celebrations locally, was clearly beneficial. Yet, as important as it may be to building awareness of difference, the staging of celebratory events would need to be accompanied by programmes that were of a more sustained nature which, ideally, would address the more mundane needs of local residents. A number of such programmes have been initiated - notably a mother and toddler group, cookery classes and a gardening group, though their establishment has not been without its difficulties. The cookery classes (for instance) sought to share culinary recipes but ensuring that the classes were sufficiently representative of the different local ethnicities required itself in effect some engineering. 


\section{Conclusions}

The relatively short history of the Hidden Gardens has raised important questions linking the design and usage of public space and the extent to which, and how, it is able to foster meaningful forms of inter-cultural dialogue. In effect the Gardens was an engineered space addressing recognition of local diversity. Yet, in the attempt it problematised how public space could be designed and used to foster inter-cultural dialogue. These questions centred on how users could (and should) use a dedicated space, processes which in giving expression to agency were to reveal its power to generate alternative readings to those intended. The tensions between these different routes in attaining durable inter-cultural dialogue became played out in the politics of the space. In itself the space directly addressed difference; the experience of its usage show how the politics of recognition needs constant reaffirmation.

These lessons from the Gardens need to be understood within the wider debates of community cohesion under New Labour and, following the election of the Coalition Government in 2010, its call for greater integration as the means for establishing social cohesion (DCLG, 2012). Both express loosely defined ideologically driven preferences whose limitations become evident through the messier realities of local practice. Building community cohesion through fostering inter-cultural dialogue is an ongoing challenge particularly in ethnically mixed neighbourhoods (Becares et al., 2010; Lancee and Dronkers, 2011). The reality is that it is through local practice that the building takes place and where the messiness of implementing nationally expressed aspirations becomes apparent. If anything this disjuncture has become more apparent through Coalition policy. The move towards integration in Coalition policy poses an apparent contradiction to what spaces such as the Hidden Gardens are trying to do, to raise awareness of difference. In Creating the Conditions for Integration Coalition policy emphasizes commonalities over difference, silencing the term multiculturalism. Yet, as in the neighbourhoods in which the Hidden Gardens were established, multicultural diversity, and the issues to which it can give rise, persist. The switch to integration in Coalition policy represents a different twist to the tensions that exist between the national context and the local level where social relations are practiced.

* Correspondence address: Ronan Paddison, School of Geographical and Earth Sciences, University of Glasgow, Glasgow, UK. Email: ronan.paddison@glasgow.ac.uk

Marilyn Keenan, School of Geographical and Earth Sciences, University of Glasgow, UK. Email: marilyn.keenan@glasgow.ac.uk

Sophie Bond, School of Geography, Environment and Earth Sciences, Victoria University of Wellington, New Zealand. Email: sophie.bond@vuw.ac.nz 


\section{References}

Amin. A. (2002) Ethnicity and the multicultural city: living with diversity. Environment and Planning $A$, 34, 959-980.

Amin, A. (2012) Land of Strangers. Cambridge: Polity.

Amin, A. and Thrift, N. (2002) Cities: Reimagining the Urban. Cambridge: Polity.

Becares, L, Stafford, M., Laurence, J. and Nazroo, J. (2010) Composition, Concentration and Deprivation: Exploring their Association with Social Cohesion among Different Ethnic Groups in the UK. Urban Studies, 48,13, 1-17.

Burnett, J. (2012) Whitening Community Cohesion? London: Institute of Race Relations. Available at http: www.irr.org.uk/news/whitening-community-cohesion/

Commission for Racial Equality (CRE) (2007) Promoting Interaction Between People from Different Ethnic Backgrounds. London: Commission for Racial Equality.

Commission on Integration and Cohesion (CIC) (2007) Our Shared Future. Wetherby: Commission on Integration and Cohesion.

Council of Europe (2009) White Paper on Intercultural Dialogue: "Living Together as Equals in Dignity." Strasbourg: Council of Europe.

Department of Communities and Local Government (DCLG) (2008) The government's response to the Commission on Integration and Cohesion. Wetherby: Communities and Local Government Publications.

Department of Communities and Local Government (DCLG) (2009a) Guidance on Meaningful Interaction. Wetherby: Communities and Local Government Publications.

Department of Communities and Local Government (DCLG) (2009b) Guidance on building a sense of local belonging. Wetherby: Communities and Local Government Publications.

Department of Communities and Local Government (DCLG) (2009c) Cohesion delivery framework. Wetherby: Communities and Local Government.

Department of Communities and Local Government (2012) Creating the Conditions for Integration. London: Communities and Local Government.

Dixon, J., Durkheim, K. and Tredoux, C. (2005) Beyond the optimal contact strategy. American Psychologist, 60, 7, 697-711.

Fincher, R. and Iveson, K. (2009) Planning and Diversity in the City. Basingstoke: Palgrave MacMillan.

Fraser, N. (1990) Rethinking the public sphere: A Contribution to the Critique of Actually Existing Democracy. Social Text, 25, 6, 56-80.

Fraser, N. (1995) From redistribution to recognition? Dilemmas of justice in a "postsocialist" age. New Left Review, 1,2, July-August, 68-93.

Glover, T.D., Parry, D.C. and Shinew, K.J. (2005) Building Relationships, Accessing Resources: Mobilising Social Capital in Community Garden Contexts. Journal of Leisure Research, 37, 4, 450-474.

Holland, C., Clark, A. Katz, J. and Peace. S. (2007) Social interactions in public spaces. York: Joseph Rowntree Foundation.

Home Office (2001) Community cohesion: A report of the Independent Review Team chaired by Ted Cantle. London: Home Office.

Lancee, B. and Dronkers, J. (2011) Ethnic, Religious and Economic Diversity in Dutch Neighbourhoods: Explaining Quality of Contact with Neighbours, Trust in the Neighbourhood and Inter-Ethnic Trust. Journal of Ethnic and Migration Studies, 37, 4, 597-618.

Laurier, E. and Philo, C. (2006) Cold shoulders and napkins handed: gestures of responsibility. Transactions of the Institute of British Geographers, 31 2, 193207.

Lownsborough, H. and Beuderman, J. (2007) Equally spaced? Public Space and interaction between diverse communities. London: Demos. 
Macey, M. (2009) Multiculturalism, religion and women: Doing Harm by Doing Good? Basingstoke: Palgrave MacMillan.

Okin, S.M. (1997) Is Multiculturalism Bad for Women? Boston Review, 22, 25-8.

Paddison, R. and Sharpe, J. (2007) Questioning the end of public space: Reclaiming control of local banal spaces. Scottish Geographical Journal, 123, 2, 87-106.

Pask, A. (2010) Public space activism, Toronto and Vancouver, In: J. Hou (ed.) Insurgent Public Space. London: Routledge, pp. 227-240.

Robinson, D. (2008) Community Cohesion and the politics of communitarianism, In: Flint, J. and Robinson, D. (eds) Community Cohesion in Crisis? New dimensions of diversity and difference. Bristol: The Policy Press, pp. 15-33.

Thrift, N. (2005) But malice aforethought: cities and the natural history of hatred. Transactions of the Institute of British Geographers, 30, 133-150.

Valentine, G. (2008) Living with difference; reflections on geographies of encounter. Progress in Human Geography, 32, 3, 323-337.

Vertovec, S. (2007) New Complexities of Cohesion in Britain: Super-Diversity, Transnationalism and Civil-Integration. London: Commission on Integration and Cohesion.

Wood, P. and Landry, C. (2008) The Intercultural City: Planning for Diversity Advantage. London: Earthscan. 